Amanda Labarea $H$.

\title{
Un estudio sobre el feminismo en Chile
}

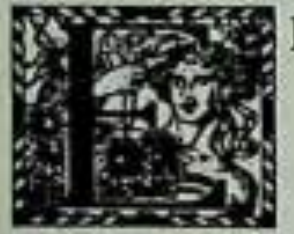

L Consejo Nacional de Mujeres de Chile que he tenido la honra de presidir. ha alcanzado no ha mucho que 14 Diputados, representantes de todos los partidos políticos, suscriban y patrocinen un proyecto de ley que tiende a mejorar la situación juridica de nuestras mujeres.

Aseguran los estadistas que el derecho se basa en los hechos y que son leyes eficaces tan sólo aquellas que vienen a consagrar las costumbres. ¿Tenemos en Chile usos y costumbres nuevas que necesiten ser legalizadas y reglamentadas por nuevas leyes? $\mathrm{Y}$ de existir tales usos chabrán las leyes de restringirlos o de fomentarlos? Este es el tema que trataré de estudiar ante vosotros.

Entre algunas ramilias en extremo pudientes y entre alguna que otra protegida bajo los hospitalarios aleros de nuestras grandes casas campesinas, se conservan todavia restos de la organización familiar de 1850 , de aquella que vivió el genial humanista, don Andrés Bello y que hubo de inspirar, en parte, el Código Civil que aủn nos rige.

Su jefe no era el padre, sino el patriarca. Abuelo las más de las veces, congregábanse a su lado las hijas, las nueras, los yernos, junto con la prole rumorosa de los nietos. Si alguna de ellas no casaba, vestal ante el fuego doméstico. quedaba alli protegida y amparada por la familia. Si enviudaba alguna, no habia que temer mayores infortunios, ni más amargos desamparos para los pequeños huérfanos. El sitio de todos estaba asegurado en el amplio hogar.

Esta comunidad protegida por el amor, la sabiduría o la prudencia del patriarca, conocía menos desgracias individuales que nuestras familias de hoy. Las dificultades de alcoba, las rencillas fraternas. suavizábanse ante el influjo cariñoso del abuelo. Representaba la tradición de paz; él. que había vivido más, sabía aconsejar. amonestar, inflingir castigos y aún perdonar mejor. En sus manos, enriquecidas de experiencia, se reunian el prestigio de la autoridad moral y la fuerza del poder financiero de los suyos. El dirigia y manejaba la común hacienda. Autoridad moral y poder material aseguran la base de un gobierno sólido. Y su gobierno era respetado en los limites de su hogar, como el de un rey en las provincias de su monarquía. 
A su lado, habia también un sitio de honor para la dulce reina de cabellos canos. En su sumisión, en su recato, era el límpido espejo en que se miraba la familia. Se hubiera dicho que no hacia otra cosa en la vida que amar a su dueño y ser adorada de los suyos. Pero no. que dirigía ella una colmena de diligentes abejas. Es una fábrica de múltiples talleres la gran casona patriarcal. Abunda alli el trabajo para todas las manos femeninas industriosas y leves. Se carda, se hila, se urden telas, cobertores, ponchos y tapices: se vacian alli mismo los cirios de las desposadas. los velones de los dias de sarao. las chisporroteantes y amarillentas lágrimas de los funerales. En otoño, en corro ante las grandes cosechas de los frutos, se desgrana el maiz; se preparan los descorazados, los huesillos. los orejones apefecidos de la chiquillada y el dulce arrope. En invierno se cose, se teje, se borda en las veladas largas, tan gratas al menudo y retozón pelambrillo. cuchicheado en voz baja para no apagar las notas cristalinas del clavicordio, ni turbar la lectura sosegada del abuelo.

¡Qué necesidad podian sentir estas mujercitas hacendosas, siempre ocupadas en sus múltiples faenas caseras, de una educación humanista! No vivian ellas para el mundo sino para gloria y dulcedumbre del ancho nido que las vió nacerl

Esa fábrica-nido no sólo formaba un reino por el régimen juridico que le reglaba. Lo era también, y de los mejores, porque constituía un centro autónomo de producción y de trabajo. Bastaban las labores de ellos mismos a subvenir a sus propias necesidades. Lo que se mercaba del exterior era cosa insignificante comparada con los productos domésticos.

Sancionó la ley esas costumbres. Nuestro Código Civil robustece la autoridad del hombre, jefe de la familia. Le concede derechos tan amplios como eran amplias sus responsabilidades: hizo de la mujer. lo que era realmente, una menor. una eferna protegida. La minoría de ésta es un derecho que la ley concede a la mujer, derecho que está asegurado por un deber del hombre: la protección. Bien claro lo estipula el art. 131 del Código Civil:

La mujer debe obediencia al marido: éste protección a la mujers.

Tal profección se extiende a la parentela. Según el Art. 321 de la misma compilación, se deben alimentos al cónyuge, a los ascendentes y descendentes legítimos, a los padres naturales, a los hijos naturales y a su posteridad legitima. a los hermanos, etc.

iCuántas de las mujeres que me escuchan y yo misma. quizá. prefeririamos haber vivido en aquella atmósfera blanda, protegidas de las celadas, de las veleidades de la fortuna y de los reveses amargos del mundol

Mas, de tales organismos familiares hoy no quedan sino restos en una que otra gran familia superviviente del pasado-y en las leyes que, tardas en transformarse. siguen viviendo cuando los que las crearon para sus usos. son polvo y ceniza en los panteones abandonados.

No es culpa de los hombres de hoy que el hogar actual no proteja a la mujer como el de hace cincuenta años. Aventáronse, no sin dolor. los miembros de la antigua familia patriarcal. El huracán de un nuevo régimen económico les desarraigó 
del hogar y les condujo a las fábricas y, poco a poco, los oficios domésticos fueron trasladándose a los talleres industriales.

Diéronse las factorias a producir mil y un artefactos, desconocidos unos, otros que antaño eran un lujo y que hoy se han popularizado pasando de la calidad de cosas superfluas a la de indispensables.

Pudieron vivir dichosos nuestros abuelos sin tranvías eléctricos, sin cocinas a gas, sin califones. $\sin$ bañeras tibias, sin telélonos, sin autos. Gratisimas eran sus veladas, sin más lumbre que la de los candiles. Hoy. el que los usa no los fabrica y la luz eléctrica ha de pagarse a un altisimo precio. Otro tanto sucede con los artefactos, los utensilios y hasta con los alimentos. Tanto el pobre como el rico han de comprarlos, nó al productor, sino al intermediario, de suerte que todos. cual más, cual menos, pagan su tributo al régimen capitalista en que vivimos.

Sólo los grandes terratenientes y los magnates de las empresas productoras. pudieran hoy día aceptar el altisimo lujo de obligarse a la protección de una familia patriarcal. Todos aquellos que no producen sino que alquilan sus servicios. ya sea en el comercio, en las industrias, en la Banca o en la burocracia adminisfrativa - y constituyen éstos la inmensa cantidad-se ven obligados, impelidos, a desentenderse de la protección que los códigos le obligan. Y ¿cómo habría de amparar y proteger aquél que apenas logra subvenir a las necesidades de su mujer y de sus contados hijos?

Protección y tutela son términos de un mismo todo. No puede estar en futelaje alguien que carece de tutor. Cuando comenzó a faltar la protección del hombre. fué cuando la mujer comenzó a ser feminista. La hermana soltera que no tuvo cabida en el reducido hogar que formaron los hermanos, la viuda abandonada que vió con pavor amenazados de miseria y de hambre a los hijos de sus entrañas, fueron las primeras en palpar la realidad del nuevo estado de cosas. Desde entonces, faltas de la protección patriarcal, han de entrar a la arena de la lucha, en un mundo cuya complejidad no conocen, para el cual rara vez están preparadas $y$ en el que no encuentran leyes que las amparen, puesto que no hay otra ley para ellas que las del hogar patriarcal que ya está aventado y deshecho.

Quiero recalcar anfe vosotros, que el régimen de producción capitalista es el que ha forzado al hombre a abandonar la profección que consagraba antaño a la mujer de su familia, y el que ha desmenuzado el hogar. de tal suerte, que hoy no presenta ni la cohesión, ni la solidez, ni la resistencia de antes.

El hogar de hoy no fiene la capacidad económica ni material suficiente para albergar más que a los cónyuges y a unos poquísimos hijos. La autoridad omnimoda reside en el joven marido, quién, ni legal ni moralmente, está obligado a aconsejarse de nadie. No le alcanzan, como antaño, la acción reguladora del padre o del abuelo. maduros en amor y en experiencia. Por el hecho de haber llegado a su mayor edad, se suponen en el joven dotes de administrador; por el de contraer bodas, calidades de director espiritual y competencia de juez. A sus manos inexpertas se entrega el patrimonio de la esposa: a su alma todavia no afinada y relemplada por el dolor, vanamente orgullosa. las más de las veces, de su juventud y de sus ilusiones, se entrega el destino de la pequeña y endeble nave conyugal. iQué 
mucho que tantas naves de éstas zozobren, arrojando de un lado un náufrago y del otro una mujer abandonada, indefensa ante las murmuraciones y la maldad del mundol

Sobre los débiles hombros de muchas mujeres. pesan hoy día las responsabilidades de protector. A falta del padre o en auxilio de éste. cientos de hermanas mayores trabajan en los talleres o en las oficinas para alimentar, vestir, educar a los pequeños: miles de mujeres viudas, antes amparadas por los suegros o los padres. luchan hoy por el pan cuotidiano de ellas y de sus hijos.

A los legisladores se han adelantado los padres. exigiendo para las niñas una educación más adecuada a la realidad de la vida. Y en este punto. la acción del capitalismo se combina con el del régimen democrático imperante.

El sufragio universal supone (aunque sea éste un desiderátum todavia lejano). la posesión de una cultura que permita a todo elector darse cuenta de los problemas vilales de su patria. y una conciencia, mas no sea intuitiva. de la solución que a tales problemas conviene. De aqui, el ensanchamiento enorme operado desde principios del siglo XIX en la educación del individuo.

Aún antes de que se vislumbrara que la mujer podia llegar a ser un elector. esa ampliación de la cultura afectó el régimen de ignorancia en que vejetaba.

Desposeida por el avance del estado industrial capitalista de las labores de su casa, dedicóse con mayor ahinco a sus sagradas tareas de madre. Necesitaba el hijo de mayor ilustración so pena de ser desterrado de la cosa pública. Acudió la madre a instruirse también. para estar a la altura de su santo ministerio.

Si la educación de la mujer se ha propagado en éste, como en los demás paises democráticos, en tal forma, que constituye uno de los fenómenos más notables de la historia moderna, es porque dos factores trascendentales se aliaron para impulsarla; espiritual el uno, su noble afán de ser una madre digna de los hijos: económico el otro, el de prever la posibilidad de quedar desamparada y de tener ella misma que subvenir a las necesidades de los suyos.

Hénos, pues. muy lejos de la situación de hecho en los años de dietación de nuestro Código Civil. Ha cambiado fundamentalmente la realidad. Existen nuevas necesidades, nuevos usos, productos, nó de los hombres en cuanto individuos, sino de la evolución general del mundo bajo el régimen capitalista y democrático.

La estadística nos enseña que existen ciento veinte mil mujeres obreras en Chile; más de veinte mil en las profesiones, el comercio y las oficinas, sobre ciento cincuenta mil niñas alumnas de las escuelas primarias, veinte mil en los Liceos. cinco mil en las escuelas profesionales y cerca de mil doscientas en la Universidad.

Cifras son éstas, que revelan un estado social profundamente diverso del de 1850 .

Dijimos no ha mucho que protección y tutela son partes de un mismo todo. Igual cosa sucede con responsabilidad y libertad. El ser libre es responsable de sus actos: quien asume responsabilidades, necesita libertad de iniciativa y de acción. 
En el hecho, la mujer chilena de hoy tiene responsabilidades crecientes y una mayor libertad. En el derecho civil, una y otra le son desconocidas.

A restablecer la armonía que debe existir entre la realidad y la ley, se han encaminado los proyectos de los senadores Briones Luco, Claro Solar, y Yáñez. Cábeles la honra de ser los iniciadores; cualquier proyecto que se presente.-incluso el nuestro del Consejo Nacional de Mujerés-ha de seguirlos, porque ellos abrieron camino y señalaron rumbos. Mas. la reforma no es sencilla. El Código Civil cristalizó la situación fotal de una sociedad; las relaciones familiares que constituian la base de ella, la condición de la mujer dentro de este régimen. estân intimamente ligados a mil otros aspectos de la jurisprudencia de entonces. de tal suerte, que al reformar unos, se afecta directa o indirectamente una serie de situaciones legales diversas.

Es un proyecto mínimo de ley el patrocinado por el Consejo Nacional de Muieres. Toca sólo aquellos puntos cuya reforma acepta unánimemente la opinión ilustrada de liberales y conservadores, de antis y de pro-ferninistas.

1.9) Abolición de las incapacidades en razón del sexo: es decir, sanción en el derecho, de la realidad actual en que la mujer desposeída de protección doméstica. necesita actuar con esa independencia que requieren las responsabilidades que a menudo ha de echar sobre sus hombros.

$2^{\circ}$ ) Concesión de la patria potestad a la madre en todos los casos en que fal. fare el padre; $y$

3.') Facultad de la mujer dentro o fuera del matrimonio, de administrar sus propios bienes.

No contiene el proyecto ni hace mención. siquiera de paso. de dos cuestiones máximas en el feminismo: el divorcio y el sufragio: lo primero. porque deseamos ardientemente evitar en las discusiones de este primer proyecto. las acritudes derivadas de las intransigencias religiosas: lo segundo, porque sufragio sin libertad civil y económica es una innoble farsa.

La fe que tengo en el hondo afán de justicia del espíritu humano, me permite esperar que los legisladores nuestros estudiarán serena y cuidadosamente el proyecto sometido a su consideración. y lo aprobarán si lo estiman justo y conveniente.

Justo y convenientel ¿Lo creerán así? Aparecerá ante ellos clara, evidente. luminosa, la justicia y la conveniencia? Si el que las leyes sancionen las costumbres, que el derecho se base en el hecho es justo, sin duda lo será un proyecto que tiende a armonizar esos dos factores. Pero Iconvenientel ¿Qué criterio ha de servirnos para saber si conviene o nó?

Entramos aqui a la parte más dificil. más debatida, más oscura de la doctrina feminista. Llegados a este punto, permitidme, que aligere ésta, que ya es una larga disquisición, con el cándido aparato de una fábula.

Érase una vez un rozal magnífico abierto a la luz del sol. Ante el hechizo de su belleza y el sortilegio sutil de su perfume, precipitábanse las abejas que iban de flor en flor llevando de una a otra el pólen fecundante. Asi crecía el rosal y se multiplicaba. 
Engreidos de tanto esplendor. los estambres, en cuyas doradas anteras maduraba el pólen. creyéndose un día la porción más importante de la flor. El Destino nos ha hecho reyes! $\operatorname{Sin}$ nosotros, oh rosal, dijeron, perderias tu efernidad. De hoy en adelante nosotros impondremos la ley a este rosal.

Medraron pues los estambres. monstruosamente, obstruyeron con su frondosidad el dulce camino de las abejas, arrebataron con su sombra la luz del sol a los pétalos que ya no refulgieron como clarines triunfales: perdió la planta la divina armonía de su arquitectura, y con la prosperidad de las flores monstruosas y estériles, se apagó la vida del rosal.

Tal es la humanidad. Hombres y mujeres son los esfambres y el giniceo de una misma flor de maravillosa arquitectura. No son seres aislados ni potencias completas en sí. Plantas existen. como la rosa, que guardan en una misma flor el secreto de sus dos sexos. Hay órdenes también en que ambos están colocados en distintos árboles o en separadas flores. Mas, ante la inmortalidad de la especie, los dos sexos, aunque contenidos en seres diferentes, no constituyen sino una sola entidad.

Al olvido de esta verdad se debe, primero, el excesivo hominismo de nuestra civilización de ayer, el avance del feminismo de hoy. Tan grave daño hacen al mundo el uno como el otro. sí, olvidando que no se quebrantan impunemente la armonía de las partes, se consideran a sí mismos aislados, y no recuerdan en todo momento que por encima de ambos, yérguese el destino de la humanidad futura.

En balde habla en nuestros corazones el instinto con la tremenda voz de los siglos. Le desoyen y le burlan los mil y un razonamientos que ha engendrado el sistema económico y social moderno. Queremos-hombres y mujeres - vivir enuestra propia vidas, a esa aberración hemos llegado!

Llenas están las novelas y dramas contemporáneos de personajes que rompen hogares. burlan compromisos y destruyen existencias en nombre del derecho del individuo a svivir su propia vida. Pero ccómo puede suceder otra cosa en esta organización económica de hoy en que la luerza y el dinero. se alian para explotar al hombre: en que a las madres y a veces hasta a los niños se les obliga a luchar por el sustento en el agrio reclutamiento de la ofería y de la demandal

Tan trabajados estamos por el capitalismo que no persibimos sus crueldades. que no comprendemos que por causa suya peligran. junto con la raza. esos ideales de perfección humana que del lobo-troglodita han hecho surgir un Platón o un San Francisco de Asis.

El niño, uncido por la necesidad al yugo de la fábrica: la madre exhausta después de un día de taller, son crimenes de humanidad. ICon qué derecho este régimen económico se permite segar en flor las energías de la raza?

Refleccionemos un instante en el número infinito de antepasados que necesitaron amar. padecer y morir para que uno de nosotros goce hoy del don inefable de la vida. ¿Qué sentido tuvo su paso por el mundo sino el de continuar una evo- 
lución espiritual cuyo término no puede ser otro que la realización en la Tierra de la Belleza, de la Verdad y del Bien Supremo?

Si la nafuraleza no ha permitido que hombres ni mujeres sean capaces por sí solos de conducir al través de los siglos el mensaje de la inmortalidad, si apenas son formas de que se vale la especie para alcanzar sus maravillosos designios, parece cosa inaudita que, cegados por los artificios de nuestra civilización, hayamos venido a suponer que hombres o mujeres pueden vivir cada cual esu propia vida.

Si creyera que el triunfo del feminismo va a fomentar esta aberración, no sería feminista. No pueden ser los nuestros exclusivos problemas de mujeres sino de humanidad; a esta luz hay que estudiarlos. A esta luz quería yo también que los legisladores les mirasen, que no pensaran en la conveniencia egoísta de ellos ni de nosotros, sino que irgiéndose por encima del individuo perecedero y efimero. acordaran su corazón a la voz del espíritu humano ansioso de justicia, de amor y de inmortalidadl

Establecido nuestro criterio. volvemos a inquirir: ¿Conviene modificar el régimen jurídico de la mujer?

Cuánto Ud. lleva dicho hasta aqui. podría responder un anti-feminista, no viene a asegurar sino ésto: que el sistema de protección era muchísimo más conveniente para la mujer. para la familia y para la humanidad que éste. que ahora Uds. pretenden sancionar con un nuevo derecho. Porque entonces la mujer, dedicada exclusivamente a la dicha, al amor y a la prosperidad de su hogar, se espaldia en hijos numerosos y sanos. No pretendia vivir egoistamente su vida. sino darse, darse a su hogar, a los suyos, a la encantadora florescencia de los retoños.

Cierto, aquel régimen tuvo partidas excelentes: pero ¿podemos volver a él? ¿Podemos retornar a la familia patriarcal?

¡Qué tremenda revolución no sería menester para destruir el capitalismo? Porque una de dos: o se es patriarcal o se es capitalista. Los dos régimenes se contraponen y si Ud. folera o admite el trabajo de la mujer y del niño en su fundo, en su fábrica o en su oficina, si Ud. no acepta que es obligación suya amparar a toda su parentela femenina. Ud. de hecho, ha abolido el sistema patriarcal y adherido al criterio industrial - capilalista de hoy. - No puede el individuo remontar el curso del tiempol $\mathrm{El}$ pasado. y aún este instante fugitivo que es el presente, adquieren por el hecho de ser. caracteres eternos é inmutables.

El capitalismo es por desgracia un hecho. Ante él no caben sino tres actitudes: el del revolucionario que intenta destruirlo. el del que lo acepta para su comodidad o conveniencia y el de quién lo estudia para mejorarlo. intimamente convencido de que ninguna organización humana, como ningún acto individual son enteramente malos ni enteramente buenos, porque mirados desde el plano de la perfectibilidad, son experiencias, tanteos necesarios para encontrar el camino de lo mejor.

Forzados a someternos ante los hechos, demos a las mujeres, salidas mal de su grado del régimen tutelar, la libertad juridica indispensable al ejercicio de sus responsabilidades nuevas. $Y$ bajo la inspiración de aquellos ideales supremos que son a nuestra vida espiritual lo que el lucero de Belén a los tres reyes, armonicemos los preceptos legales con los categóricos imperativos de la realidad. 
Tres puntos, dije. que tocaba nuestro proyecto. El primero, la anulación de las incapacidades por razón de sexo. De buenísimo grado os ahorro. los argumentos que todos conocéis para probar el derecho de la mujer a que se la considere como persona. Eso, no lo discufe ningún ser razonable. Ni os exhibiré tampoco las argumentaciones de quienes indagan si la mujer puede o nó alcanzar el genio, si es o nó susceptible de conceptos abstractos, si es o nó capaz de orientarse en el sublime laberinto de la metafísica. Antójanseme tales disquisiones tan pueriles, tan bizantinas como aquella famosa disputa medioeval sobre el número de dientes de los caballos. Hasta que después de años de enconada controversia, alguien alzó el bello de su cabalgadura y le contó los dientes.

A buen seguro que a Mme. Curie o a Selma Lagerlöft, la genial novelista laureada con el Premio Nobel, les tienen muy sin cuidado las discusiones de los hombres sobre el talento femeninol Son éstos. hechos que los tiempos y no las disquiciciones habrán de aclarar.

Solo dos detalles me parecen dignos de que nos detengamos un instante en ellos.

Aconsejábarne no ha mucho un amigo mio, diciéndome: No sea Ud. tan celosa en la propagación de sus ideales. ¡Lo que Uds, van a ganar en derechos lo van a perder en encantos!.

Quién así me hablaba era un experto catador de feminidades: un hombre que entraba precisamente en esa edad, para muchos tan sugestiva, que a causa talvez de las canas que comienzan a platear los cabellos negros, apodan los franceses, la edad de la pimienta y la sal.

Expresaba èl lo que muchos sienten. Mas. ¿no es éste acaso un espejismo sintimental? Añoran el arquetipo de mujer que encantó sus ensueños de adolescente. IA ése echan de menos y no otrol La Mimi todavía impregnada del perfume de la época romántica: delicada, Trágil, rosa de pasión vestida de azucena mistica. Empero. es aquél un tipo único y eterno? Cada civilización ha producido uno distinto. Recuérdese, si no las magníficas dogaresas del Renacimiento, frutas doradas por el sol de todas las pasiones; las lindas damiselas de Versalles; las matronas del Directorio: todas diferentes, todas cautivadoras. Acaso la mujer de mañana no conozca la gracia humilde y dócil de la enamorada de ayer. Será distinta: su alma nueva le dará encantos nuevos. Se adaptará instintivamente a la clase de civilización y al tipo de hombre que habrá de elegirla. ¡Es inmortal y eferno como la raza, el secreto encanto femeninol

Con apariencias más graves se presenta la segunda objeción. Aseguran algunos que la extensa cultura y libertad. apartará a la mujer del matrimonio y que el exceso de trabajo intelectual le arrebata sus atributos de madre.

En parte tienen razón. Las condiciones legales del matrimonio en Chile, no son halagũeñas para las jóvenes habituadas al ejercicio de una vida de trabajo y de responsabilidades. Dada la extensión de la cultura que ciertas niñas de nuestra sociedad reciben. les es bien dificil, además, encontrar entre los mozos de su generación y clase, un marido a la altura de sus justas aspiraciones. Pero es que la vida ha cambiado, se ha modificado la cultura, se han trocado las cosfumbres, y sôlo la ins- 
titución matrimonial perdura rigida y sensible a los ayes de miles de desgraciados que hacen una vida común de crueldades o hipocresías o se apartan trágicamente. - rompen la valla del vínculo y lo disuelven con la complicidad de la ley.

Tales desgracias no hay que colocarlas a la cuenta del ferninismo. sino a la de un derecho en que los muertos mandan, obligándonos a regir situaciones vivas con usos difuntos.

$\mathrm{Y}$ cuanto a que el esfuerzo intelectual sea nocivo a las tareas de la maternidad. es probable que tengan razón. Pero convengnmos, que es cierto, tanto para la mujer como para el hombre, y que es verdad no solo del trabajo intelectual, sino de toda labor excesiva. Ojalá que podamos ver el momento en que por lo menos durante los diez primeros años de matrimonio, la madre, aún la más pobre, la más infeliz. pueda verse libre de toda faena, que no sea la de cuidar sus propios hijos. |Ay| Pero será posible, mientras perdure esta sociedad capitalista? Lo dudo mucho.

El segundo punto de nuestro programa. la concesión de la patria potestad a la madre en todos los casos en que fallare el padre, no necesila de mayores discusiones. Si, lo ha menester, el de la comunidad o separación de bienes en el matrimonio:

La comunidad de bienes y la administración exclusiva del marido son demasiado tentadores para el joven esposo. sobre todo si éste pasa violentamente de la calidad de hijo pobre de una familia adinerada (pobre, porque aún no ha recibido su patrimonio, ni está habituado a un trabajo productivo) a poscedor de una riqueza de cuya administración no tiene que dar cuenta a nadie, mientras no se le pruebe que ya la ha dilapidado. Es también un incentivo para el ocioso. casado con una mujer trabajadora. Miles de estos casos ocurren a diario en la clase media y pobre. Infelices mujeres que trabajan dificultosamente, que aceptan sacrificios sin cuento para ganar un pan que dedican a sus hijos y que en un minuto echa el marido a los vientos de su ociosidad o de sus vicios.

Estos defectos del régimen han sido corregidos de diversas suertes en las legislaciones modernas $y$ aún en aquellas que precedieron al Código de $\mathrm{Na-}$ poleón.

El 9 de Agosto de 1793 en las postrimerias de la Revolución Francesa, Cambacérès propuso a la Convención Nacional el texto siguiente:

Los esposos tienen igual derecho para la administración de sus bienes. Todo acto importante, venta, compromiso, obligación o hipoteca sobre los bienes del uno o del otro no es válido sino ha sido consentido por ambos cónyuges.

Los esposos pueden obligarse separada o reciprocamente para negociar, pero en este caso. será necesaria la declaración previa y auténtica de su voluntad mutua. (1).

(1) Joly.-Le Droit Feminin.-Pog. 60. 
IEra una admirable, profunda y justa manera de concebir la comunidad conyugal!

Entre los Códigos modernos, el Alemán de 1900, repudiando ya toda idea de incapacidad de la mujer. establece para ésta. bienes exclusivos de su sola administración, en los que incluye los objelos-muebles que sirven a las necesidades y a las industrias propias de la mujer, todo lo que adquiera directamente por su propio trabajo y cuanto constituya indirectamente con lo que ha podido economizar (1).

El Código Civil Francés actual, admite en principio que los esposos, o más bien los padres que presiden la unión, son libres de escoger el tipo de contrato conyugal que más les convenga. Les ofrece tres clases fundamentales: el de separación de bienes, el de la comunidad y el régimen dolal.

El mismo Código ofrece combinaciones de ellos. de modo que puede aceptarse una comunidad limitada a los bienes que se adquieran durante el curso del matrimonio, dejar separados ciertos aportes, en común otros, etc.

En Suiza, cualquiera que haya sido el régimen financiero en que se hayan desposado, la ley permite que, a petición de cualquiera de los cónyuges, se revise y se modifique el contrato.

Prevalece en los países escandinavos, en Inglaterra y en Estados Unidos el sistema de separación.

El proyecto presentado al Congreso Chileno por el Senador Don Luis Claro Solar sigue al Código Alemán, el de Don Eliodoro Yáñez, que hemos aceptado nosotros en esta parte, establece como régimen normal el de la separación de bienes.

A la joven de mayor edad le permite nuestro Código Civil la libre administración de su fortuna: la supone, por lo tanto. capaz de hacerlo. ¿Por qué lo habría de ser menos la mujer casada? Porque está bajo la influencia del amor, porque por desarrugar el ceño de su esposo, puede arrojar al viento su patrimonio, sin que en ello quepa responsabilidad alguna del marido. $Y$ ahora, con responsabilidad del mismo. si le apefece empobrecerla ¿no lo hace de igual modo? ¿Qué sanción ni qué castigo recibe? ¡Qué holgadas cárceles se necesitarian si se recluyese en ellas a todos los que han empobrecido a su mujer y a sus hogares!

Lo que habria que preguntarse es si el régimen de separación favorece o nó la armonia intima del hogar y. por ende. la suerte de los hijos.

Desde luego. disminuiria el número de esos ruines negocios que se llaman matrimonio de conveniencia: permitiria a la mujer trabajadora. y ninguna alquila sus servicios si no lo necesita para si o para los suyos, defender su salario de la dilapidación del marido, y excluiría de la vida conyugal las odiosas discusiones de dinero. Recuérdese también que la separación de bienes no excluye la posibilidad de que en un matrimonio armónico la esposa instituya administrador a su marido. Este, lealmente interesado en la suerte de su mujer y los hijos, hará en tal caso una administración ideal. ITan cierto es que el amor no necesita de leyesl Cuándo en la tierra reine la caridad que predicó Jesús, y se ame en verdad al prójimo como a si mismo. holgarán las Cortes de Justicia, los Gobiernos y los Códigos! No se legisla para los justos sino para los pecadores.

(1) Henri Joly.-Le Droit Ferninin.-Pag. 70. 
Uno de los argumentos que se presenta contra el régimen de separación es el de que desposeerá a la mujer viuda de los gananciales. Separada de bienes, ella pasaría a heredar en forma semejante a la de los hijos.

Los gananciales eran una equitativa consecuencia del sistema patriarcal de familia. Allí donde ésta, bajo la experimentada dirección de la madre, elaboraba mayor número de productos que los que obtenía el hombre con el dinero o con el fruto de su propio trabajo, era lógico que se considerara que la mitad por lo menos de la fortuna conyugal se debia al desvelo y al trabajo de la esposa.

No ocurre hoy otro tanto: el hogar no es productor sino consumidor y cuanto más puede hacer la mujer, es gobernarlo con tal economia y discreción que nada se desperdicie ni malgaste. Mientras una esposa de éstas es un factor, no de ingresos sino de economía, otra mujercita atolondrada hace de su casa un tonel de las Danaides. En ambos casos, el marido puede construir una fortuna con su profesión, y a su muerte chay equidad en que ambos reciban la mitad de la riqueza conyugal?

Si el proyecto presentado por el Consejo Nacional de Mujeres pasara a ser ley de la República, la madre viuda tendría la patria potestad en la misma forma que el padre; administraria, por lo tanto, con amplios poderes la forluna suya y la de los hijos. A falta de gananciales, se le concede el derecho de percibir y disponer de los intereses de su buena administración.

Dueño será el marido, también, de disponer a favor de su esposa, de la cuarta de libre disposición, que asi la recibiría quien fuese en verdad digna de ella. Una pequeña reforma de la ley en lo que se refiere a las herencias, podria asegurar también a la mujer casada bajo el régimen de separación, una parte proporcional del haber que se obtuviere durante el matrimonio.

En conclusión, el feminismo nació cuando la organización capitalista vino a reemplazar al de la familia patriarcal, porque el hombre hubo de desentenderse de la protección con que antaño amparaba a la mujer y ésta tuvo que salir a la arena del mundo, para una lucha que el régimen capitalista hace cada día más agria. más cruenta, más impía.

Mientras este sistema reine omnipotente, el hogar sufrirá las consecuencias y por ende la humanidad del futuro. No exigimos reivindicaciones femeninas, porque las consideramos un ideal; nó, sino porque dado el sistema económico y social que nos rige, son indispensables para aliviar la crueldad de muchas injusticias.

Yo espero que ha de llegar un día en que en la mente de los hombres brille la luz, como para Saulo en el camino de Damasco: que sientan, que se compenetren que el capitalismo industrial de hoy. en que obtienen los más altos precios la materia, el dinero, el capital, es un tipo de civilización que está matando la vitalidad de la raza, que está destruyendo la alegría de los hombres, el encanto de| hogar y el porvenir espiritual del mundo.

$\mathrm{Y}$ entonces no habrá temenismo ni hominismo: oiremos la voz imperiosa de los siglos y sobre la ley del hombre se cernirá la ley inmortal del amor. 